\title{
Introduction: 'Some for All Rather than More for Some'? Contested Pathways and Politics since the 1990 New Delhi Statement
}

\author{
Alan Nicol, Lyla Mehta and Jeremy Allouche
}

\begin{abstract}
This introduction reviews the experience of the water and sanitation sector since the $1990 \mathrm{New}$ Delhi Statement - Some for All Rather than More for Some. It explores the policy pathways and contested politics that took place as a result of three key years in the early 1990s, from the issuing of the New Delhi Statement in 1990, through the Dublin Statement on Water and Sustainable Development in 1992, to the output of the Earth Summit held in Rio de Janeiro. These key events have shaped policy and practice over a period of two decades, including generating major contestation over the idea of water as an economic good. Past lessons suggest that the wider global water and sanitation community needs to rethink approaches and emphases, shifting from targets and global pronouncement to issues concerning sustainability, global/local mismatches, contested knowledges, equity, politics and power.
\end{abstract}

\begin{abstract}
1 Introduction
Access to water and sanitation for all is central to achieving global justice for poor people. Yet the global aid architecture is still straining to solve what appears to be on the surface, a simple problem: how to provide water and sanitation to the planet's population. Despite successive global declarations and efforts, in 2008 over 2.6 billion people still lived without access to improved sanitation facilities and nearly 900 million people received drinking water from unimproved sources (WHO 2010). At the core of this appalling situation is a global failure of collective action, despite repeated principles, declarations and meetings.
\end{abstract}

The 1977 Mar del Plata Conference was the first - and still the only - global conference on water held under United Nations auspices. This international awareness-raising led directly to the UN International Drinking Water Supply and Sanitation Decade (1981-90), known as the 'Water Decade', which had lofty ambitions including universal coverage by 1990. At the end of the decade, the target still remained far off, not least because of the huge debt crisis that had engulfed many developing countries during this period. To assess what had happened and to look towards future pathways for collective action, in 1990 the UN held a global consultation in New Delhi hosted by the Indian government. As we approach another major juncture $-2015^{1}$ - and further global events in 2012 (the sixth World Water Forum and Rio+20) - this IDS Bulletin looks back at the legacy of New Delhi (and the Dublin conference that followed), assesses their meaning and significance, and challenges the wider global water and sanitation community to rethink approaches and emphases, shifting from targets and pronouncement to sustainability and local knowledge.

Under the slogan, 'Some for All Rather than More for Some', the New Delhi Statement was expected to set a course for the global community to follow in the $1990 \mathrm{~s}$, mindful that progress had not been satisfactory during the previous decade and that a far larger global meeting was scheduled for 1992 - the Earth Summit in Rio de Janeiro. Few today, however, are aware of New Delhi and its statement of intent, the event having been eclipsed by the 


\section{Box 1 Guiding Principles of the New Delhi Statement}

\section{Principle No 1}

The Environment and Health emphasised waste management and the need for Integrated Water Resources Management (IWRM). Communities should be an equal partner in this with government and sector agencies. Indigenous knowledge was important and lent credence and relevance to policies and programmes. This was linked to a focus on education, social mobilisation and community, and the seeking of solutions that were environmentally appropriate and affordable 'to the communities they serve'. IWRM was, it argued, also necessary to combat increasing scarcity and pollution. This was an early area of IWRM thinking, which was subsequently to become a dominant paradigm during the 1990s. It was innovative - and ahead of its time in some ways - in emphasising the need to integrate wastewater treatment more effectively (see Kamal Kar, this IDS Bulletin).

\section{Principle No 2}

People and Institutions focused on establishing strong institutions amidst an 'enabling environment of appropriate policies, legislation and incentives', and warned against targets taking precedence over capacity building. Government roles should become those of 'promoters and facilitators', enabling local public, private and community institutions to deliver better services. The importance of decentralisation was emphasised as well as local private enterprise to improve efficiency and expand service delivery. There was a heavy emphasis on non-governmental organisations (NGOs), including extolling governments to support them in replicating approaches and include them as partners. The statement also made strong reference to training, education and curricula development. This was infused with experience from the 1980s, and particularly the challenges and failures of government supply-led approaches. It was also the first sign of a wider ideological battle over the role of the State in development.

International Conference on Water and the Environment (ICWE) held in Dublin, 26-31 January 1992. Notorious for its 'fourth Principle' (discussed below and the major reason it captured global attention), Dublin has been a focus of policy differences and global fault lines ever since. Some argue that this has actually hampered global efforts at achieving the elusive goal of universal coverage, if not the less ambitious but more pragmatic 'Some for All' of New Delhi. Was Dublin a necessary (re)emphasis, or a form of ideational sabotage?

Looking back at the intervening 21 years was the objective of Liquid Dynamics II, the second STEPS Water and Sanitation Symposium entitled 'Some for All? Politics and Pathways in Water and Sanitation since New Delhi, 1990', held at IDS, 22-23 March 2011. Bringing together current thinkers and past architects of the New Delhi Statement, as well as academics and those deeply involved in current policy and practice, the meeting posed questions, including: Why has the nature of collective action been so convoluted in addressing what is an easily definable problem? Are global declarations and targets as much a part of the problem as the solution and how do they match with the on-theground realities of poor women and men? Are there alternatives to the dominant paradigms and pathways as exemplified in big pronouncements from global policy meetings?

\section{New Delhi to Dublin and Rio: a policy scramble}

The New Delhi Statement was presented as an appeal for concerted action and adopted at the Global Consultation on Safe Water and Sanitation for the 1990s. This event was cosponsored by the UN Steering Committee for the International Drinking Water Supply and Sanitation Decade and by the Water Supply and Sanitation Collaborative Council, established just prior to the meeting (see Jon Lane, this IDS Bulletin). The statement underscored that insufficient progress had been made during the Water Decade, and recommended four guiding principles for the future:

- Protection of the environment and safeguarding of health through the integrated management of water resources and liquid and solid wastes; - Institutional reforms promoting an integrated 


\section{Principle No 3}

Community Management emphasised empowering and equipping communities to 'own and control their own systems', which would help to ensure sustainability in service delivery. Communities should have 'prominent roles in planning, resource mobilization, and all subsequent aspects of development', including women 'playing influential roles in both water management and hygiene education'. An emphasis was placed on linkage between national plans and community 'needs and desires'. This principle was heavily influenced by ideas emerging of Village-Level Operation and Maintenance (VLOM). This notion sat alongside a wider view that localised approaches could help to ensure sustainability through reducing the distance between manager and user of the resource. As we will see below, however, this assumed a kind of ideal type community on which could be pegged management responsibilities.

\section{Principle No 4}

Finance and Technology called for more effective financial strategies for long-term sustainability, suggesting that to fill the funding gap, there should be increased efficiency in use of available funds and mobilisation of additional funds from existing and new sources, including governments, donors and consumers. Consumer choice of technology and service levels had proved to have had 'a positive impact on cost recovery and sustainability'. Given the debt burden of countries at the time, agencies and donors were 'urged to look favourably on requests for grants or soft loans to support water and sanitation programmes'. The statement added that setting user charges was a key issue in sector finance and the recovery of recurrent costs was emphasised alongside widespread promotion that 'safe water is not a free good'. This suggested that alongside greater community management could sit community financing, with the end-user paying for access to the resource. The principle may have been sound, but in many cases, the practice was difficult - communities were not set-up to manage finances and to seek payments from different households (and to deal with issues of free-riding).

approach and including changes in procedures, attitudes and behaviour, and the full participation of women at all levels in sector institutions;

- Community management of services, backed by measures to strengthen local institutions in implementing and sustaining water and sanitation programmes;

- Sound financial practices, achieved through better management of existing assets, and widespread use of appropriate technologies.

Each principle had an accompanying text, summarised in Box 1.

The consultation was expected to lead to national-level action plans for water and sanitation, incorporating these principles, and was presented by the Indian government to the 45th Session of the United Nations General Assembly in October 1990. This was part of what the organisers anticipated would be a wider influencing agenda by the global water community on the forthcoming Earth Summit in Rio de Janeiro. In fact, however, the New Delhi Statement was rapidly overshadowed by the
'Dublin Statement', the product of a meeting held in January 1992 under the auspices of the World Meteorological Organization (WMO) and as a preparatory meeting for Rio.

Varady and Iles-Shih (2009) (and others) identify Dublin as the single most important global water initiative, whereas New Delhi merits no place within their analysis (Varady and Iles-Shih 2009: Table 1.3). This raises important questions some of which are touched on in this IDS Bulletin - about the way in which processes and messages in global public policy are formed, attain influence and, ultimately gain or lose legitimacy. A particular emphasis of Dublin was on the fourth Principle - water as an economic good. In full, this stated:

Water has an economic value in all its competing uses and should be recognized as an economic good: Within this principle, it is vital to recognize first the basic right of all human beings to have access to clean water and sanitation at an affordable price. Past failure to recognize the economic value of water has led to wasteful and environmentally damaging uses of the 
Table 1 The New Delhi and Dublin Principles

\begin{tabular}{ll}
\hline New Delhi Principles & Dublin Principles \\
\hline $\begin{array}{l}\text { Protection of the environment and safeguarding of } \\
\text { health through the integrated management of water } \\
\text { resources and liquid and solid wastes }\end{array}$ & $\begin{array}{l}\text { Fresh water is a finite and vulnerable resource, essential } \\
\text { to sustain life, development and the environment }\end{array}$
\end{tabular}

Institutional reforms promoting an integrated approach and including changes in procedures, attitudes and behaviour, and the full participation of women at all levels in sector institutions

Community management of services, backed by measures to strengthen local institutions in implementing and sustaining water and sanitation programmes

Sound financial practices, achieved through better management of existing assets, and widespread use of Water development and management should be based on a participatory approach, involving users, planners and policymakers at all levels

Women play a central part in the provision, management and safeguarding of water

Water has an economic value in all its competing uses and should be recognised as an economic good appropriate technologies

Source United Nations (1990 and 1992).

resource. Managing water as an economic good is an important way of achieving efficient and equitable use, and of encouraging conservation and protection of water resources. (WMO n.d.)

Comparing the major headline statements from New Delhi and Dublin reveals that although similarities existed, this fourth Principle established the major divergence between the two meetings. Dublin made a centrepiece out of economic valuation of the resource, which was seized upon by powerful institutions (the World Bank in particular) and became part of the wider Washington Consensus, under which the State's role was expected to shrink, and there was greater adherence to free-market capitalism and the commoditisation of resources (Finger and Allouche 2002). Water as an 'economic good' sat comfortably within this newly emerging consensus.

The strength of Dublin was not just that this principle chimed with a new development paradigm, but that it also resonated with Agenda 21, Chapter 18 on Freshwater (United Nations 1992; Salman 2003, 2004). This stated that: 'Integrated water resources management is based on the perception of water as an integral part of the ecosystem, a natural resource and a social and economic good, whose quantity and quality determines the nature of utilization'. It also stressed 'the implementation of allocation decisions through demand management, pricing mechanisms, and regulatory measures'. ${ }^{2}$ Further discussion of this interrelationship can be found in Philippe Cullet's article in this IDS Bulletin.

In short, economic valuation of the resource rapidly became part of wider debates on environmental resources and water scarcity more generally (Mehta 2010). Winpenny (1994: 18) argued that this new approach to valuation would increase water supply coverage and encourage private investment as 'low prices depress the profitably of investment in the water sector'. The enabling environment for such a policy would include the clear separation between operator and regulator, as well as measures that provided for real costs, water tariffs, and demand management.

Declaring water an economic good in Dublin remains to this day deeply controversial. Many in the global water community still feel this not only legitimises the 'commodification' of a lifegiving resource, but also continues to justify potential privatisation and resource capture (most recently manifested in 'water grabs' taking place under wider land grabbing). Strictly speaking, economic goods are goods that are scarce and legitimise human action and market intervention (Mehta 2010), which, in so doing, privileges certain types of meaning and beliefs over others, including cultural and public good aspects. This privileging is part of the wider contestation over policy approaches to solving 
the massive gap in access to water supply and sanitation that has persisted to this day.

\section{Reassessing patterns and pathways}

In some ways, both New Delhi and Dublin remain part of a far larger issue which extends across the global community, namely how global events and processes establish 'privilege' and replicate simplistic visions of reality in order to arrive at specific policy prescriptions. What stood out in the meeting was that a far more complex and denser reality exists. At the STEPS Centre, we have termed this complex relationship Liquid Dynamics - the often neglected patterns of interaction between the social, technological and ecological dimensions of water and sanitation which raise important questions about access, complexity, uncertainty, sustainability, politics and power in water and sanitation (see Mehta et al. 2007). The following sections present key perspectives from the symposium on these and other issues.

\subsection{Politics (not) as usual}

Emerging from the discussions and papers was the strength of political activity at all levels, shaping and reshaping actors, relationships and processes of policy development and implementation. A global 'high politics' of water developed during the 1990s, dissociated and increasingly lacking in legitimacy but driven forward by meetings of dubious global legitimacy (Gleick and Lane 2005), while at a local level, a politics of power and control continue to shape outcomes for poor men and women.

Pathways - the ways complex systems evolve over time - are influenced by politics and power. The dominant pathway in global approaches to the water and sanitation challenge is to seek ambitious targets (but frequently fail to assess why efforts often fall short of expectation). The call for greater political will is often heard, but the more complex and nuanced environments (and institutions) confound a simple championing approach. Gourisankar Ghosh (this IDS Bulletin) underscores the important collaboration that took place between UN agencies and governments during the 1980s UN Water Decade but argues that subsequent bias by some institutions led to a focus on Dublin - and water as an economic good - including recasting New Delhi's 'Some for All' call as a recipe for free water. It was not, he emphasises, but once the shift of emphasis had taken place to economic tools a decade of missed opportunities resulted. Certain pathways had asserted themselves.

A notion of what one may term 'high water politics' infuses Philippe Cullet's piece (this IDS Bulletin). He sees a turning point in the way policy and law has been constructed during the 1990s. The wider institutional and political landscape shifted significantly after New Delhi, leading to a crisis of legitimacy and a blurring of the distinction between policy and legal process. There has been a bypassing of democratic and public mechanisms in favour of less public and less transparent structures. The Dublin Principle on water as an economic good, Cullet argues, has been the single most important change to water policy, leading to a focus on demand management and increases in water use efficiency. He argues, however, that these Principles lacked legitimacy and had no UN General Assembly endorsement.

Suneetha Dasappa Kacker and Anuradha Joshi (this IDS Bulletin), looking at the role and regulation of small-scale informal service providers in New Delhi, highlight a key relationship between providers and consumers - what we call a kind of 'low water politics'. Central to this relationship is the role of political awareness and competition at a community level, enabling a break from clientilism with local elites and stronger engagement with public service providers. The importance of informality (filling a need/demand) and the relationship to local political actors is often reinforcing rather than reforming, with local leaders having vested (and hidden, perhaps) interests in continued informal provision. In some cases, this has meant 'Some for All' becoming the reality of less and less for all. Yet these and other challenges have led to local political (re)action, with residents' groups petitioning government on the right to water supply and the responsibility of government to provide for this, echoing a more recent shift to rights-claiming based on an emerging global consensus on the human right to water and sanitation.

Reflecting back on global water events, and to the Delhi-Dublin episode, a legitimacy crisis has emerged at national and in some cases, local levels. Global events in the water sector represent the presence of a strong epistemic community, but one which lacks cohesion and a common measure - and sense - of legitimacy. However, the 
strength of these events in future could (and should) be their capacity to provide a vehicle for multiple alternative voices, including emerging human rights-based views. A stronger, more cohesive and legitimate architecture for public policy debate on water issues has to emerge.

\subsection{Knowledge - contested and convoluted}

International events may propel forward policy ideas and global public awareness of key problems, but they can also help to concretise misconceptions of progress and shape perceptions of what (and whose) knowledge counts more (or most even) in addressing water and sanitation issues.

Synne Movik (this IDS Bulletin) challenges the dichotomisation that has emerged in the last two decades between public and private (in part due to the New Delhi-Dublin fault line) and suggests that needs and models should fit circumstances. Using a South Africa example, she notes how target-driven approaches to provisioning free basic water under a 'Some, for All, for Ever' motto devolved responsibilities to municipalities, where the urge to reach universal coverage encouraged target-driven approaches based on infrastructure development at the expense of 'functioning and quality of service delivery'. In the urge to reach universal coverage, 'the ability to actually meet needs is compromised', representing a shortfall in wider understandings of social, environmental as well as technical sustainability.

Contestations along a public-private fault line are the subject of Mohamad Mova Al 'Afghani's article on Indonesia (this IDS Bulletin), where the private sector model - and concessionary contracts - were tried during the 1990s, mirroring attempts at 'bringing the private sector in', but led to a rash of movements aimed at preventing private sector engagement. The notorious Jakarta concession for water supply is an example of how a lack of regulation and control affected major water supply initiatives; but he shows how other publicly oriented approaches in Indonesia are less ambiguous on rights, roles and responsibilities - and (potentially) more successful as a result.

The critical knowledge embedded locally in addressing future challenges such as climate change and impacts on water supplies is central to the analysis of Rajasthan by Michael Mascarenhas (this IDS Bulletin). He highlights the importance of local knowledge in terms of adaptation to climate uncertainty, noting the importance of local institutions in 'nurturing practice that advances both household social reproduction and women's status within the community'.

Gaining new knowledge is a contested and sometimes politically driven process. The donor world has a particularly poor record of seeking out new numbers. Katharina Welle et al. (this IDS Bulletin) examine the experience of the National WASH Inventory process in Ethiopia and question the underutilisation of sector monitoring results. The authors locate this in processes of knowledge creation linked to power and political economy at a national level. This includes institutional inertia and the bundling together of institutions with different mandates under a WASH umbrella, and to donor push, resulting in data collection as mass mobilisation, rather than a deeper learning and experience sharing process.

Integration of different knowledge systems - the expert and lay - is the substance of an article by Tim Karpouzoglou and Anna Zimmer (this IDS Bulletin). Examining how integration of different 'knowledges' within policymaking on wastewater can take place, they argue that this resonates strongly with the New Delhi Statement's call to strengthen citizens' participation in the implementation of water and sanitation programmes. Examining a wastewater case study from the same city, they note that engineering works become 'markers of development', within which the knowledge of local communities is lost. The value of citizens' accounts lies not only in addressing the politics of wastewater in an elaborate way, but in directing attention to complex social and environmental impacts of untreated wastewater. The authors conclude that wastewater issues often lack their own policy space.

How knowledge is shaped and institutionalised affects the ease of future integration. An emerging lesson from these case studies is that neglect of local knowledges can lead to a serious lack of social, economic and technological sustainability in the future. Acquisition of knowledge is also an important tool in its own right, bringing different actors together in a process of deliberation on resolving different development challenges. 


\subsection{Sanitation - old issues, new dynamism}

One of the most important shifts since New Delhi has been a growing focus on sanitation including new solutions to this old problem. A policy space has emerged, within which there are new dynamics, but also familiar problems of global statements not being followed up on by action, particularly at national government level. The role of government in addressing the sanitation gap is now more complex, but essential to address, particularly as parallel campaigns seek to underscore the right to sanitation and, at the same time, decry the past failure of government-subsidised approaches.

Looking back at the last two decades based on field knowledge and deep engagement in policy processes, Jon Lane (this IDS Bulletin)

emphasises that progress has been achieved and stresses that the world is 'slightly better off' in terms of water supply. However, progress in the last 20 years has not closed the sanitation gap and the Millennium Development Goal (MDG) on improved sanitation will be missed by about a billion people in 2015. He notes, however, that neglect of sanitation has begun to change and the huge benefits to improved sanitation are beginning to be understood, including the 'sound financial' practices, emphasised in New Delhi.

New Delhi's emphasis on locally appropriate technologies is echoed in Duncan Mara's examination (this IDS Bulletin) of technological solutions, including arborloos for low-density rural areas and simplified sewerage for highdensity urban areas. The former provides a connection between sanitation services and deriving value as a result - 'excreta in, money out', as he puts it. But, he argues, in spite of affordable options, there is a real problem of lack of commitment by developing country governments. Although some have led to great improvements - Malaysia and Thailand are cited - he believes that three key hindrances remain: a lack of 'thinking clean' among senior politicians; technical ignorance among local engineers; and excessive corruption.

In the past decade, Community-led Total Sanitation (CLTS) has emerged as a powerful way to address the sanitation crisis. In this IDS Bulletin, Kamal Kar, the pioneer of this approach, argues for collective behaviour change on a major scale using CLTS, an 'innovative approach for empowering communities, to completely eliminate open defecation'. This is achieved through a process of collective local action with no individual hardware subsidy and no prescribed models. He states that some 50 countries in Asia, Africa and Latin America have now adopted the approach. The global impact of this approach is echoed in a number of the articles in this IDS Bulletin.

In the past 20 years, sanitation has become far less of a taboo topic and, with that, greater understanding has emerged of potential solutions. However, the globalisation of this analysis and the institutionalisation of knowledge in major global events points to history repeating itself, possibly leading to a surfeit of debate and policy contestation over practical action. Even promising approaches such as CLTS still need to address the critical issues of sustainability and inclusivity.

\subsection{The community as entry point - and myth}

Embedded in the notion of community is a preconception about their being able and willing to exercise management functions in the delivery of water and sanitation. This is challenged at many levels by these IDS Bulletin authors. There are concerns that the often fragmented and politicised nature of communities belies a capacity to choose technologies, and that issues of equality and marginalisation are often overlooked. There is also a sense in some places that communities are constructed as failures, thus legitimising top-down resettlement and planning processes leading to complex, new, urban spaces in which access to water and sanitation may actually deteriorate.

The Swajaldhara programme in India was a flagship water and sanitation programme of the 1990s, built on principles of cost recovery and demand-responsiveness. Shilpi Srivastava (this IDS Bulletin) examines this programme and shows how global policy ideas and prescriptions can frequently be undermined locally: 'A basic underlying assumption of the scheme was that cost sharing would enable participation and implementation of ownership of water assets'. But this was based on the idea of a homogenous community, which was more fiction than reality and, in spite of a demand-led approach, government was often still regarded as the provider, responsible for any mismanagement. Although designed to be bottom-up, Swajaldhara 
in fact became embedded in a top-down model of service delivery.

Delhi's fractured State with its elite biases has produced several resettlement colonies and planned slums, 'where the state exists through its absence, and residents exist in an ahistorical space', argues Nishtha Mehta (this IDS Bulletin). In these spaces of neglect and absence, NGOs emerge as effective intermediaries between residents and public agencies, reflecting by default (and not design perhaps) another key focus of the New Delhi Statement on the role of NGOs in development planning and implementation. However, Mehta argues that fragmentation of the state in Delhi is evident in planned peripheral developments that lack basic amenities but which provide NGOs with a point of entry. However, rather than fill a void left by government inaction in these new communities, NGOs should challenge current political structures by increasing the autonomy of community residents.

The lack of community homogeneity is unpacked in this IDS Bulletin by Ravi Narayanan et al. Exclusion is a major problem, and those who are 'shut out' need urgent attention. A conscious focus on equity and ensuring that accessible and affordable services are available to all is critical, and must include addressing attitudinal, environmental and institutional barriers, including poor accountability mechanisms. Presenting a number of examples in South Asia the authors show how equity and inclusion can be mainstreamed, but need to include better indicators for those who are most difficult to reach. The authors propose the application of an equity and inclusion lens to existing monitoring frameworks covering the range of stakeholder, policy and practice dimensions.

Equity and sustainability are the focus of Barbara Frost's contribution to this IDS Bulletin. She discusses how WaterAid has evolved as an NGO over the past 30 years. WaterAid seeks to build partnerships with local government, local civil society organisations and private sector providers to ensure that communities are adequately supported to manage services on a sustainable and equitable basis.

In sum, unlike the assumptions of global statements from New Delhi to Dublin, the community is not a static idea, but is a dynamic and changing entity. Since the 1990s, many arenas have changed substantially, including how communities communicate within and between themselves, but also how the classic urban-rural dichotomy is increasingly blurred. In such a rapidly changing world, it is easy for donors and practitioners to forget the most vulnerable and marginalised, who often present a barrier to overall success and achieving targets. But it is precisely this group that needs the most attention, if equity and social justice are to be attained at all in water and sanitation.

\section{Where to next?}

The issues presented above are at the heart of the work undertaken by the STEPS Centre. ${ }^{3}$ The notion of Liquid Dynamics helps us address interdisciplinary perspectives and practical action to tackle upfront, the challenges of sustainability, uncertainty and social justice in water and sanitation access. These dynamics have often been ignored in conventional policy approaches. Instead, water and sanitation debates continue to be framed in technocratic terms, disconnected from the everyday needs of poor and marginalised women and men, and are frequently polarised, highly charged and oversimplified.

It is time to move beyond conventional indices of sustainability - and those definitions of water and sanitation problems and solutions - that tell us little about equity, pro-poor agency, power and resilience. The strength of global action now needs to be measured in terms of social, technical or financial sustainability, as well as political embeddedness, from local political action to higher-level political will. The water and sanitation sector needs to take diverse understandings of value, cost, inclusivity and equality on board, and these need to find their way into current political and policy responses to technical, physical and social challenges. These must avoid the simplistic notion of 'community', drawing on the views and experiences of the poorest and most marginalised and taking on board the many influences of political history and culture.

In 2015, the UN International Decade for Action 'Water for Life' ends and the MDG targets will come under a critical spotlight. This will be another global policy juncture. We hope that the underlying message of this IDS Bulletin - that it is vital not to forget the past and rush to new futures 
- will become part of global public discourse in the coming post-MDG world. More complex development pathways with new narratives are emerging, including a focus on the human right to water and sanitation and links between economic growth and poverty reduction and water supply and sanitation. Further challenges and fault lines are to be expected, but understanding more fully how we have arrived at the current situation is key

\section{Notes}

1 This is both the end of the UN 'Water for Life' Decade 2005-15, see www.un.org/ waterforlifedecade/ and the due date for the Millennium Development Goals.

2 From Agenda 21, Chapter 18, paragraphs 18.6 and 18.8, as adopted by the United Nations

\section{References}

Finger, M. and Allouche, J. (2002) Water Privatisation: Transnational Corporations and the Re-regulation of the Global Water Industry, London: Taylor and Francis

Gleick, P.H. and Lane, J. (2005) 'Large International Water Meetings: Time for a Reappraisal', Water International 30.3: 410-14

Mehta, L. (2010) (ed.) The Limits to Scarcity: Contesting the Politics of Allocation, London: Earthscan

Mehta, L.; Marshall, F.; Movik, S.; Stirling, A.; Shah, E.; Smith, A. and Thompson, J. (2007) Liquid Dynamics: Challenges for Sustainability in Water and Sanitation, STEPS Working Paper 6, Brighton: STEPS Centre

Salman M.A. Salman (2004) 'From Marrakech through the Hague to Kyoto: Has the Global Debate on Water Reached a Dead End? Part Two', Water International 29.1: 11-19

Salman M.A. Salman (2003) 'From Marrakech through the Hague to Kyoto: Has the Global Debate on Water Reached a Dead End? Part One', Water International 28.4: 491-500

United Nations (1992) The Dublin Statement on Water and Sustainable Development, International to understanding future pathways to more effective global collective action.

In another 21 years, the world will be approaching its peak population of 9 billion people. If problems of access to water and sanitation persist, our global collective failure will be of epic proportions and 'Some for All' will remain an ever-more-distant goal.

Conference on Environment and Development, Rio de Janeiro, June 1992, www.unep.org/Documents/ (accessed 21 December 2011).

3 www.steps-centre.org/ (accessed 21 December 2011).

Conference on Water and the Environment, Dublin, 31 January 1992, www.ielrc.org/content/ e9209.pdf (accessed 1 December 2011)

United Nations (1990) New Delhi Statement, Global Consultation on Safe Water and Sanitation, 1990, www.ielrc.org/content/e9005.pdf (accessed 1 December 2011)

Varady, R.G. and Iles-Shih, M. (2009) 'Global Water Initiatives: What do the Experts Think?', in A.K. Biswas and C. Tortajada (eds), Impacts of Megaconferences on the Water Sector, Berlin: Springer-Verlag: 53-101

Winpenny, J. (1994) Managing Water as an Economic Resource, London: Routledge

WHO (2010) UN-Water Global Annual Assessment of Sanitation and Drinking-water (GLAAS) 2010: Targeting Resources for Better Results, Geneva: World Health Organization

WMO (World Meteorological Organization) (n.d.) The Dublin Statement on Water and Sustainable Development, www.wmo.int/pages/ prog/hwrp/documents/english/icwedece.html (accessed 21 December 2011) 